\title{
EFFECT OF SALT AND WATER STRESSES ON GROWTH, NITROGEN AND PHOSPHORUS METABOLISM IN CUCUMIS SATIVUS L. SEEDLINGS
}

\author{
Elżbieta SacaŁa, Anna Demczuk, Edward Grzyś, Zofia Spiak \\ Department of Plant Nutrition, \\ Wrocław University of Environmental and Life Sciences \\ Grunwaldzka 53, 50-357 Wrocław, Poland \\ e-mail: elzbieta.sacala@up.wroc.pl
}

(Received: January 2, 2007. Accepted: July 5, 2007)

\begin{abstract}
Plants exposed to osmotic stress exhibit changes in their physiology and metabolism. In general, osmotic stress reduces water availability and causes nutritional imbalance in plants. In the present study, we compared the response of cucumber (Cucumis sativus L. var. Władko F-1) to ionic (100 mmol.dm $\left.{ }^{-3} \mathrm{NaCl}\right)$ and osmotic stress (10\% PEG 6000). Both stress factors reduced significantly fresh and dry weight of 7-day-old cucumber seedlings. Under PEG treatment reduction of cucumber dry mass was lesser than in fresh mass, whereas under salt stress decrease in dry weight of cucumber shoots was more pronounced than in fresh mass. Salt stress caused severe decrease in nitrate concentration and activity of nitrate reductase (NR). In cotyledons nitrate content declined to $17 \%$ of the control and similar reduction in NR activity was observed. In the roots, observed changes were not so drastic but there was also strong interaction between reduction in nitrate content and NR activity. Under $10 \%$ PEG both nitrate concentration and NR activity in cucumber roots were significantly higher in comparison to control plants. In cotyledons NR activity was significantly lower than in control plants, while decrease in nitrate content was not statistically significant. Phosphate concentration did not change significantly in cucumber cotyledons but increased in roots treated both $\mathrm{NaCl}$ (32\% increase) and PEG (53\% increase). Similar tendencies were observed in acid phosphatase activity. Obtained results indicated that osmotic and salt stresses evoke differential responses, particularly in growth reduction and nitrogen metabolism in cucumber seedlings.
\end{abstract}

KEY WORDS: salinity, osmotic stress, nitrate reductase, phosphorus, cucumber.

\section{INTRODUCTION}

Salinity and drought are important stress factors that limit plant growth and development. Both stress factors generate non-specific osmotic stress that is a consequence of decreased osmotic potential in rooting medium. Salinity induces additional negative effect that includes specific ion toxicity. In general, osmotic stress reduces water availability and causes nutritional imbalance in plants (ion excess or deficit) (Grattan and Grieve 1999). To maintain turgor and prevent water losses, plant cells must readjust their osmotic potential. This can be achieved by uptake of inorganic ions from external solution or synthesis and accumulation of organic compounds (compatible solutes). Among compatible solutes crucial role play compounds containing nitrogen (Mansour 2000). Thus, nitrogen metabolism and nitrate reductase (NR) activity may play significant role in acclimatization of plants to stress conditions. Besides nitrogen, phosphorus is another essential macronutrient that plays important role as a structural and regulatory element in plant growth and development. Most plant processes require phosphorus but very little is known about alteration of phosphorus metabolism under stress conditions. It is well known that in salinized media the uptake of mineral nutrients is inhibited. This negative effect includes the uptake of nitrogen which is quantitatively the most important for plant. Literature data shows that salinity reduces nitrate absorption and alters nitrogen metabolism (Mansour 2000). On the contrary, literature data concerning the interaction between salt/osmotic stress and availability of phosphate are contradictory. It was reported that salinity induces phosphorus deficiency in some plants and this effect may reduce the cellular tolerance for ion accumulation under salt stress (Gibson 1988; Kaya et al. 2001). However, some reports indicate that salinity cause an excessive accumulation of phosphate and induce $\mathrm{P}$ toxicity in the shoot (Nieman and Clarck 1976; Cerdà et al. 1977). Some investigators maintain that adequate phosphorus nutrition may minimize salt toxicity and ameliorate negative effects of water stress (Kaya et al. 2001; Shubhra et al. 2004).

The major goal of the present study was to compare the responses of cucumber (Cucumis sativus L. var. Władko) to ionic $\left(100 \mathrm{mmol} \cdot \mathrm{dm}^{-3} \mathrm{NaCl}\right)$ and osmotic stress $(10 \%$ PEG 6000). We concentrated on the analysis of interaction 
between nitrate reductase activity and nitrate content, and phosphatase activity and phosphate content.

\section{MATERIALS AND METHODS}

All experiments were conducted on cucumber seedlings (Cucumis sativus L. var. Władko F-1) grown in hydroponic cultures. Osmotic stress was induced by adding to growth medium $\mathrm{NaCl}$ or non-penetrating polyethylene glycol (PEG 6000). There were following combinations: 0.33-strength Hoagland nutrient solution (control), 0.33 Hoagland solution with the addition of $100 \mathrm{mmol} \cdot \mathrm{dm}^{-3} \mathrm{NaCl}$ (salt stress) and 10\% PEG (water stress). Culture conditions were as follows: $16 \mathrm{~h}$ photoperiod $\left(220 \mathrm{\mu mol} \cdot \mathrm{m}^{-2} \cdot \mathrm{s}^{-1}\right)$ at $26 / 20^{\circ} \mathrm{C}$ day/night, $65-70 \%$ relative humidity. After 7 days of cultivation there were investigated growth parameters, concentrations of inorganic phosphate and nitrate, and activity of nitrate reductase and acid phosphatase. Nitrate reductase activity was assayed in vivo according to the method of Jaworski (1971). The plant tissues (1 g) were cut into $5 \mathrm{~mm}$ segments and placed in phosphate buffer $(0.1$ $\mathrm{mol} \cdot \mathrm{dm}^{-3} \mathrm{~K}_{2} \mathrm{HPO}_{4}-\mathrm{KH}_{2} \mathrm{PO}_{4}, \mathrm{pH} 7.5$ contained $0.5 \%$ isopropanol). The incubation medium did not contain exogenous nitrate. The tubes were vacuum infiltrated for $2 \mathrm{~min}$ and then incubated in the dark at $25^{\circ} \mathrm{C}$ for $1 \mathrm{~h}$. The amount of nitrite formed during the reaction was measured spectrophotometrically at $540 \mathrm{~nm}$ after adding 1\% sulphanilamide in $100 \mathrm{mmol} \cdot \mathrm{dm}^{-3} \mathrm{HCl}$ and $0.02 \% \mathrm{~N}$-naphtyl-ethylenediamine. For extraction of acid phosphatase $0.5 \mathrm{~g}$ of fresh plant material was ground in cold mortar with $5 \mathrm{~cm}^{3}$ of acetate buffer $\left(0.05 \mathrm{~mol} \cdot \mathrm{dm}^{-3}, \mathrm{pH} 5.0\right)$. After centrifugation $\left(12000 \times \mathrm{g}\right.$ for $10 \mathrm{~min}$ at $\left.4^{\circ} \mathrm{C}\right)$ the supernatant was used for determination of acid phosphatase activity using 4-nitrophenyl phosphate (4-NPP) as enzyme substrate. The reaction mixture $\left(0.2 \mathrm{~mol} \cdot \mathrm{dm}^{-3}\right.$ acetate buffer, $\mathrm{pH} 5.0$, supernatant, $\left.0.06 \mathrm{~mol} \cdot \mathrm{dm}^{-3} 4-\mathrm{NPP}\right)$ was incubated at $37^{\circ} \mathrm{C}$. After $10 \mathrm{~min}, 10 \mathrm{~cm}^{3} \mathrm{NaOH}\left(0.1 \mathrm{~mol} \cdot \mathrm{dm}^{-3}\right)$ was added to terminate the reaction and to develop the colour by 4-nitrophenyl (4-NP) formed. The absorbance was measured at 410 $\mathrm{nm}$. For determination of nitrate content, $1 \mathrm{~g}$ of plant fresh material was extracted with distiled water at $100^{\circ} \mathrm{C}$ for 10 min. After filtration through Whatman No. 1 filter paper nitrate was determined colorimetrically using $5 \%(\mathrm{w} / \mathrm{v}) \mathrm{sa}-$ licylic acid in concentrated $\mathrm{H}_{2} \mathrm{SO}_{4}$. The colour was developed after $20 \mathrm{~min}$ incubation at ambient temperature by the addition of $2 \mathrm{~mol} \cdot \mathrm{dm}^{-3} \mathrm{NaOH}$. After cooling the mixture to room temperature the absorbance at 410 was measured. For total inorganic phosphorus estimation, $0.5 \mathrm{~g}$ of plant material was extracted in $8 \mathrm{~cm}^{3} 6 \%$ trichloroacetic acid and cen-

\section{A) FRESH WEIGHT}

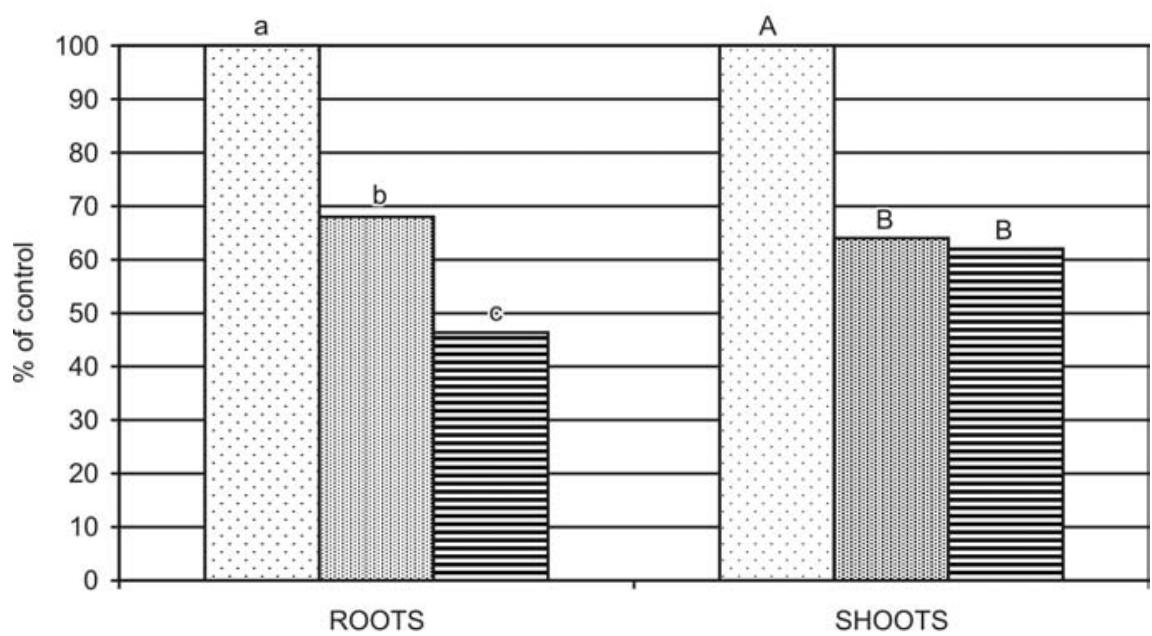

B) DRY WEIGHT

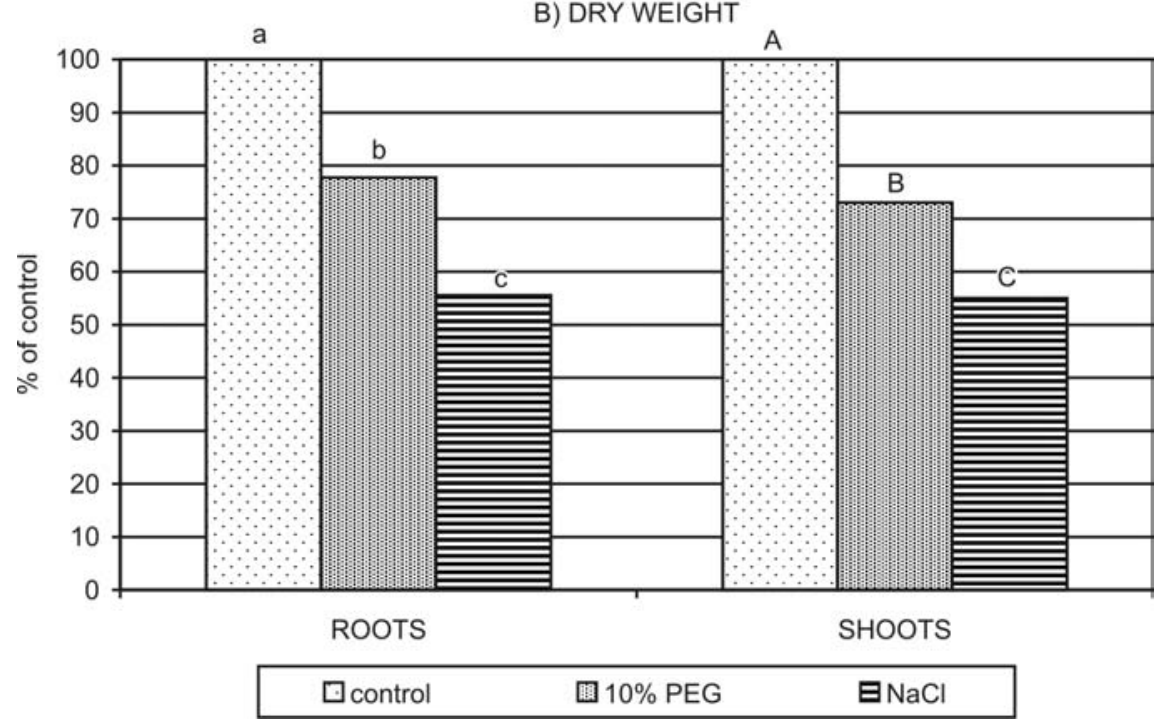

Fig. 1. The influence of $10 \%$ PEG and 100 $\mathrm{mM} \mathrm{NaCl}$ on fresh (A) and dry (B) weight of roots and shoots (hypocotyl + cotyledons) of 7-day old cucumber seedlings. The values marked with the same letter do not differ significantly $(1 \%)$. 
trifuged for $15 \mathrm{~min}$ at $18000 \times \mathrm{g}$. Phosphate in supernatant was determined colorimetrically after adding $5 \mathrm{~mol} \cdot \mathrm{dm}^{-3}$ $\mathrm{H}_{2} \mathrm{SO}_{4}, 2.5 \%$ ammonium molybdate and $0.25 \%$ 1,2,4-aminonaphtholsulfonic acid solution. After 15 min incubation at $37^{\circ} \mathrm{C}$ the absorbance was measured at $660 \mathrm{~nm}$.

The water content of plants tissues was determined by weighing the material immediately after sampling, drying at $85^{\circ} \mathrm{C}$, and reweighing $24 \mathrm{~h}$ later. The water content (WC) is expressed on a fresh weight (FW) basis and it was computed as the difference between fresh weight and dry weight, divided by fresh weight and multiplied by $100 \%$.

All experiments were repeated six times and each value is the mean of six independent experiments. Obtained values were analysed statistically using least significant difference $(\mathrm{LSD}, \mathrm{p}=0.01)$.

\section{RESULTS}

Both stress factors ( $\mathrm{NaCl}$ and $\mathrm{PEG}$ ) caused significant decrease in growth parameters (Fig. 1) moreover plant growth was more reduced by salinity than PEG. Fresh weights of cucumber roots grown under PEG and $\mathrm{NaCl}$ were respectively 32 and 54\% lower than in control plants. Ro-
TABLE 1. Water content in different organs of 7-day-old cucumber seedlings grown under $100 \mathrm{mmol} \cdot \mathrm{dm}^{-3} \mathrm{NaCl}$ and $10 \%$ PEG.

\begin{tabular}{lccc}
\hline & \multicolumn{3}{c}{ Water content [\% of fresh weight] } \\
\hline Roots & Hypocotyls & Cotyledons \\
\hline Control & $96.7 \pm 0.3$ & $96.1 \pm 0.4$ & $92.4 \pm 0.8$ \\
$\mathrm{NaCl}$ & $96.1 \pm 0.3$ & $96.4 \pm 0.3$ & $93.3 \pm 0.2$ \\
$10 \%$ PEG & $95.9 \pm 1.0$ & $96.1 \pm 0.3$ & $91.7 \pm 0.3$ \\
$\mathrm{LSD}_{0.05}$ & 1.2 & 1.2 & 1.1 \\
\hline
\end{tabular}

ots dry weight was reduced by $22 \%$ under PEG treatment and by $44 \%$ under $\mathrm{NaCl}$. In both cases reduction in fresh weight was more pronounced than in dry weight. $\mathrm{NaCl}$ and PEG caused similar decrease, approximately $40 \%$, in fresh weight of cucumber shoots (hypocotyl + cotyledons) but there was $45 \%$ decrease in dry weight under salt stress and $27 \%$ reduction under PEG treatment. Examined stress factors did not cause marked changes in water content in different organs of cucumber (Table 1). $\mathrm{NaCl}$ induced large decrease in nitrate concentration in roots and cotyledons of cucumber (Fig. 2A). Nitrate concentration in cucumber roots under salt stress comprises scarcely $29 \%$ of the control and in cotyledons it was only $17 \%$. Presence of PEG in nu-
A) NITRATE CONCENTRATION

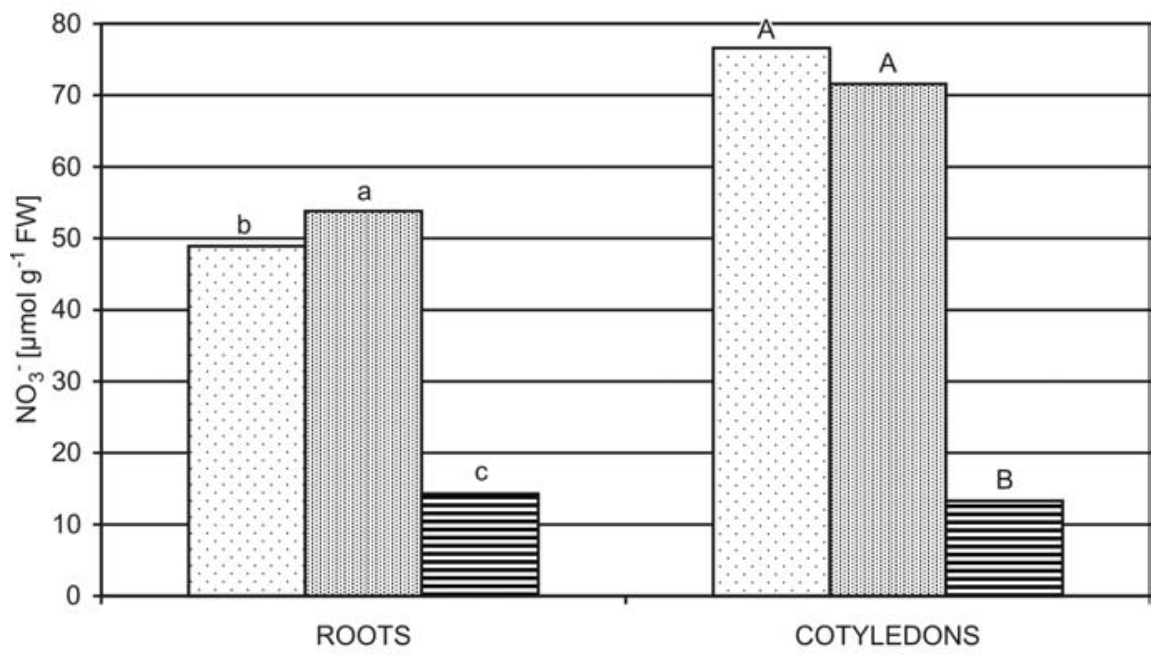

B) NITRATE REDUCTASE ACTIVITY

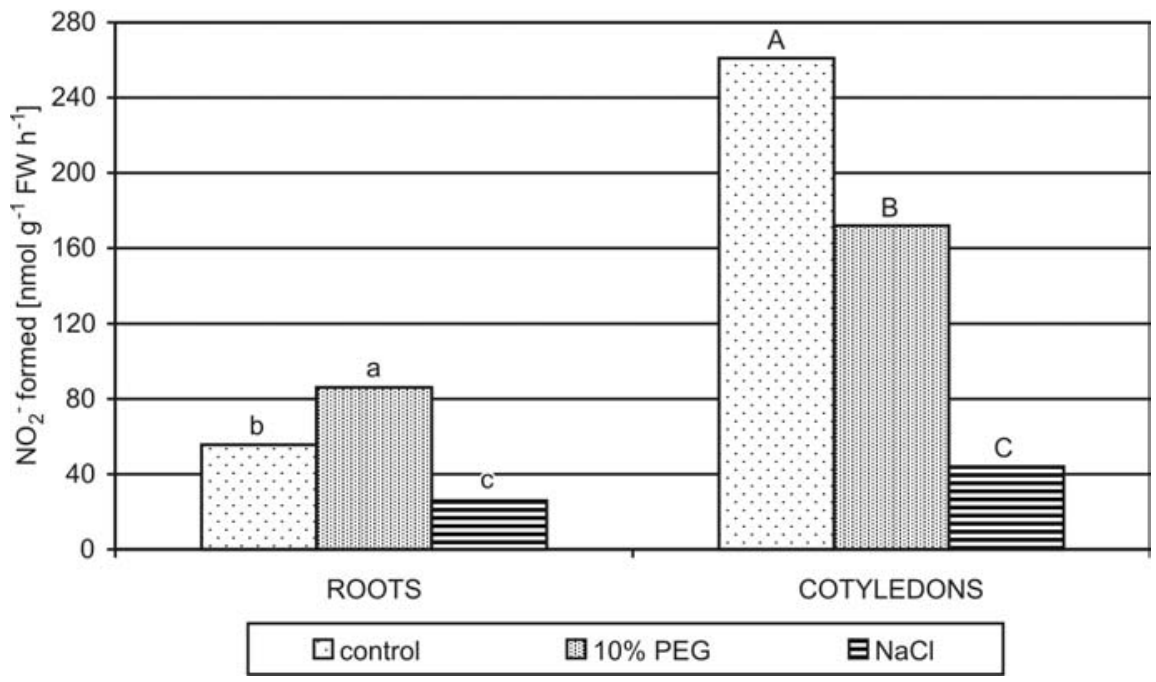

Fig. 2. The influence of $10 \%$ PEG and 100 $\mathrm{mM} \mathrm{NaCl}$ on nitrate concentration (A) and nitrate reductase activity $(\mathrm{B})$ in roots and cotyledons of 7-day old cucumber seedlings. The values marked with the same letter do not differ significantly (1\%). 
A) PHOSPHATE CONCENTRATION

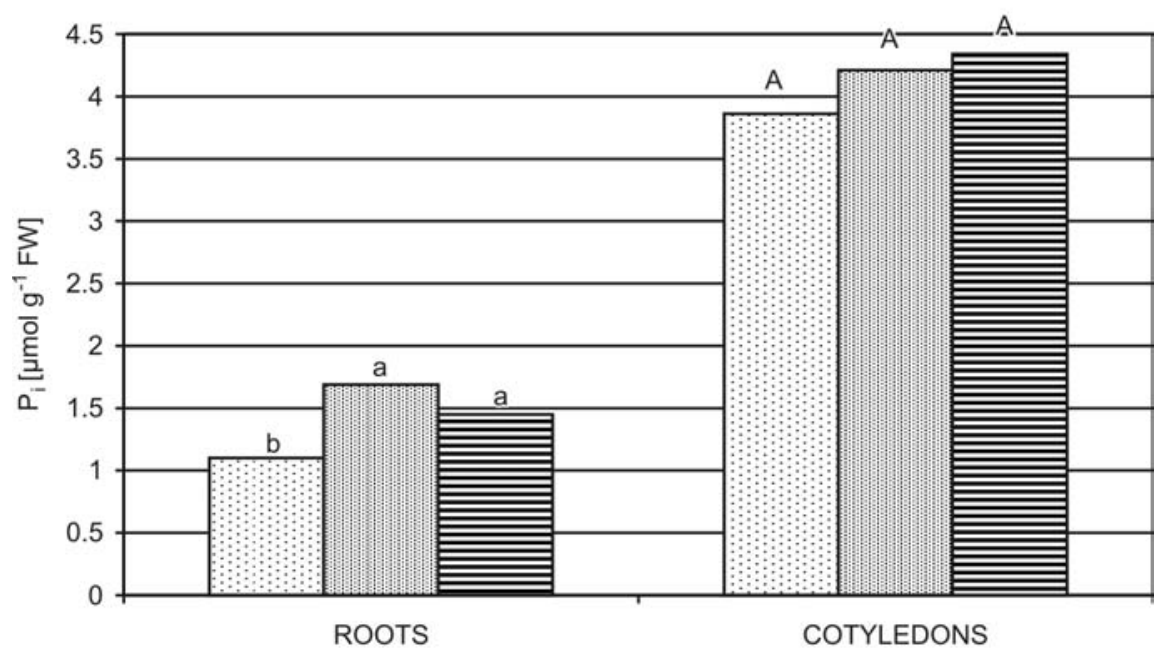

B) ACID PHOSPHATASE ACTIVITY

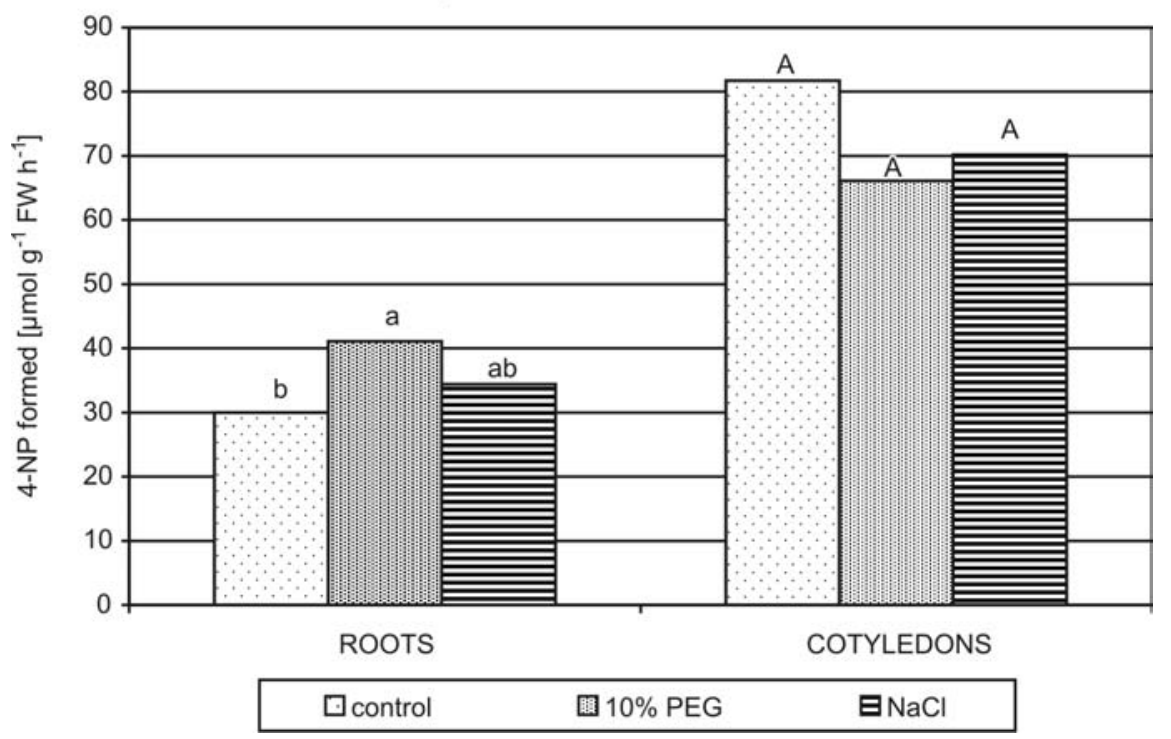

trient solution caused little but statistically significant increase $(10 \%)$ in nitrate content in cucumber roots while in cotyledons PEG did not change significantly $\mathrm{NO}_{3}{ }^{-}$concentration. Level of nitrate concentration in cucumber organs corresponded to nitrate reductase activity (Fig. 2B). Under $\mathrm{NaCl}$ stress nitrate reductase activity in roots and cotyledons of cucumber dramatically declined. Whereas, under PEG treatment, it increased (20\% in comparison to control) in roots and declined slightly in cotyledons. Both stress factors did not influence of phosphate concentration in cotyledons but caused noticeable increase in phosphate concentration in cucumber roots (Fig. 3A). Under PEG treatment and salt stress phosphate concentration in roots increased approximately of $53 \%$ and $32 \%$ in comparison to control. Similar tendencies were observed in the case of acid phosphatase activity. Both stress factors caused significant increases in enzyme activity in cucumber roots (Fig. 3B). Acid phosphatase activity increased by 35 and $20 \%$ respectively under PEG and salt treatments. Whereas, decline in phosphatase activity in cotyledons was not statistically significant.
Fig. 3. The influence of $10 \%$ PEG and 100 $\mathrm{mM} \mathrm{NaCl}$ on phosphate concentration (A) and acid and phosphatase activity (B) in roots and cotyledons of 7-day old cucumber seedlings. The values marked with the same letter do not differ significantly (1\%).

\section{DISCUSSION}

Primary consequence of salinity and drought is osmotic stress, which creates decrease in water availability. Decreased water potential of the rooting solution may lead to water deficit in plant tissues and loss of plants turgor. Our observations indicate that turgor of cucumber seedlings grown under PEG and $\mathrm{NaCl}$ was not reduced and water contents in different organs were similar to these in control plants (Table 1). Statistically significant decline in water content in cucumber shoots was observed under $15 \%$ PEG (non-published data). These results might suggest that osmotic adjustment in cucumber seedlings is very efficient. Similar effect was observed in several plants grown under mild salinity in the short term (Abd-El Baki 2000; Sacała et al. 2002; El-Tayeb 2005). Both stress factors caused significant decrease in growth parameters moreover salt stress was more detrimental than osmotic stress (Fig. 1). Growth suppression by salinity is typical response of salt sensitive plants and glycophytes. The reduction in growth might be due to toxic effect of ions, ionic imbalance and disruption of homeostasis. In our investigations, PEG treatment caused higher reduction in fresh weight of cucumber 
seedlings than in dry weight. Decrease in fresh and dry matter accumulation may be partly a consequence of disruption of ions supply in plants. This is particular evident under salt condition. Salt stress caused sharp decline of nitrate contents in cucumber organs (Fig. 2A). Numerous studies have shown that the exposure to $\mathrm{NaCl}$ stress inhibits nitrate uptake (Word et al. 1986; Botella et al. 1994; Khan and Srivastava 1998) and results in decreased nitrate content in plants tissues (Hu et Schmidhalter 1998). Nevertheless, results of some investigations showed that nitrate level in plants is not modified by $\mathrm{NaCl}$ treatment (Farias de Aragao et al. 1997). Our observations are consistent with opinion of Kaiser and Huber (2001) that NR in plants growing in stress conditions can be under strong substrate limitation. Accordingly, the main reason for inhibition of NR activity under salt stress is rather substrate deficiency than specific salt toxicity. It is well documented that nitrate reductase activity is regulated by $\mathrm{NO}_{3}{ }^{-}$(Hoff et al. 1994; Abd-El Baki et al. 2000). In our investigations, NR activity was measured in vivo without exogenous substrate. Such obtained results show the real rate of NR activity and they reflect not only the enzyme capacity but also the availability of necessary reductants and endogenous nitrate. Under salt stress conditions plants use metabolic energy to osmoregulation and prevention of ions accumulation to toxic level. Decreased energy availability and nutritional imbalance (dramatic decrease in nitrate content) might have a serious consequence in plant metabolism and growth. Most of literature data show that nitrate reductase activity decreases under salt stress (Khan and Srivastava 1998; Abd-El Baki et al. 2000; Sacała et al. 2002; Sacała et al. 2005). Thus, we assume that the decline in NR activity under $\mathrm{NaCl}$ stress is predominantly due to a decreased nitrate supply.

Another relationships occurred under PEG treatment (Fig. 2). Nitrate content and nitrate reductase activity significantly increased in cucumber roots. However, in spite of a good nitrate status in cotyledons, there was marked decrease in NR activity but this inhibition was not as dramatic as under salt condition. In this case, nitrate uptake and accumulation were not affected hence NR activity might be limited by nitrate availability. It is likely that under PEG treatment nitrate was accumulated in vacuole (it may serves as osmoticum) and this resulted in decreased metabolic pool of nitrate in cytosol. Similar conclusion proposed Talouizite and Champigny (1988). They suggested that increase in the storage pool of nitrate in shoots under drought stress is related to its role as an osmoticum. Nitrate reductase is considered as an enzyme sensitive to water stress (Barathi et al. 2001; Burman et al. 2004) but in our investigations, imposed stress factors did not change plant turgor and water content in examined organs of cucumber (Table 1).

Alterations in phosphorus metabolism were not so dramatic as that in nitrogen metabolism. Phosphate concentration increased slightly in cucumber roots under both stress factors and did not change significantly in cotyledons (Fig. $3 \mathrm{~A})$. But the increase in inorganic phosphorus pool was to small to contribute in osmotic adjustment in cucumber roots. Literature data regarding the interaction between salt/osmotic stress and phosphorus status in plants are contradictory. Rogers et al. (2003) maintain that salt stress does not inhibit phosphate uptake if concentration of phosphorus in rooting medium is high or non-limiting. Our experiments were conducted in hydroponic culture and phospho- rus availability in nutrient solutions was not generally limited. However El-Tayeb (2005) found that mild salt stress $\left(50 \mathrm{mmol} \cdot \mathrm{dm}^{-3} \mathrm{NaCl}\right)$ does not alter phosphorus content in barley roots and decreases in shoots. Whereas, higher salt concentrations $\left(100,200 \mathrm{mmol} \cdot \mathrm{dm}^{-3} \mathrm{NaCl}\right)$ resulted in significant decline in phosphorus level in plant tissues. Some scientists have suggested that application of phosphorus might improve tolerance of plant to drought and salinity (Goutierrez-Boem and Thomas 1998; Kaya et al. 2001; Burman et al. 2004; Qadar and Ansari 2006).

\section{CONCLUSIONS}

Obtained results indicated that osmotic and salt stresses evoke differential responses of cucumber seedlings, particularly in growth reduction and nitrogen metabolism. Salt stress is more detrimental than sole osmotic stress (PEG treatment). $\mathrm{NaCl}$ induces nitrate deficiency in roots and cotyledons, which corresponds to reduction in nitrate reductase activity. Whereas, 10\% PEG causes significant increase in both nitrate accumulation and nitrate reductase activity in roots. In cotyledons NR activity was significantly lower than in control plants, while the decrease in nitrate content was not statistically significant. Alterations in phosphorus metabolism were not so dramatic as that in nitrogen metabolism.

\section{ACKNOWLEDGEMENTS}

We thank E. Mordak for technical assistance and some chemical analysis.

\section{LITERATURE CITED}

ABD-EL BAKI G.K., SIEFRITZ F., MAN H.-M., WEINER H., KALDENHOFF R., KAISER W.M. 2000. Nitrate reductase in Zea mays L. under salinity. Plant, Cell Environ. 23: 515-521.

BARATHI P., SUNDAR D., RAMACHANDRA REDDY A. 2001. Changes in mulberry leaf metabolism in response to water stress. Biol. Plant. 44: 83-87.

BOTELLA M.A., CERDÀ A., LIPS S.H. 1994. Kinetics of $\mathrm{NO}_{3}{ }^{-}$ and $\mathrm{NH}_{4}{ }^{+}$uptake by wheat seedlings. Effect of salinity and nitrogen source. J. Plant Physiol. 144: 53-57.

BURMAN U., GARG B.K., KATHJU S. 2004. Interactive effects of thiourea and phosphorus on clusterbean under water stress. Biol. Plant. 48: 61-65.

CERDÀ A., BINGHAM F.T., HOFFMAN G. 1977. Interactive effect of salinity and phosphorus on sesame. Soil Sci Soc. Am. J. 41: 915-918.

EL-TAYEB M.A. 2005. Response of barley grains to the interactive effect of salinity and salicylic acid. Plant Growth Regul. 45: 215-224.

GIBSON T.S. 1988. Carbohydrate metabolism and phosphorus/salinity interaction in wheat (Triticum aestivum L.). Plant and Soil 111: 25-35.

FARIAS DE ARAGAO M.E., DA GUIA SILVA LIMA Y.J.M., DE MELO D.F., DIZENGREMEL P. 1997. NaCl-induced changes of NAD (P) malic enzyme activities in Eucalyptus citriodora leaves. Trees 12: 66-72.

GOUTIERREZ-BOEM F., THOMAS G.W. 1998. Phosphorus nutrition affects wheat responses to water deficits. Agron. J. 90: 166-171.

GRATTAN S.R., GRIEVE C.M. 1999. Salinity - mineral nutrient in horticultural crops. Scientia Horticulturae 78: 127-157. 
JAWORSKI E.G. 1971. Nitrate reductase assay in intact plant tissues. Biochem. Biophys. Res. Commun. 43: 1274-1279.

HOFF T., TRUONG H.-N., CABOCHE M. 1994. The use of mutants and transgenic plants to study nitrate assimilation. Plant Cell Environ. 17: 489-506.

HU Y., SCHMIDHALTER U. 1998. Spatial distributions and net deposition rates of mineral elements in the elongating wheat (Triticum aestivum L.) leaf under saline soil conditions. Planta 204: 212-219.

KAISER W.M., HUBER S.C. 2001. Post-translational regulation of nitrate reductase: mechanism, physiological relevance and environmental triggers. J. Exp. Bot. 52: 1981-1989.

KAYA C., HIGGS D. KIRNAK H. 2001. The effects of high salinity $(\mathrm{NaCl})$ and supplementary phosphorus and potassium on physiology and nutrition development of spinach. Bulg. J. Plant Physiol. 27: 47-59.

KHAN M.G., SRIVASTAVA H.S. 1998. Changes in growth and nitrogen assimilation in maize plants induced by $\mathrm{NaCl}$ and growth regulators. Biol. Plant. 41: 93-99.

MANSOUR M.M.F. 2000. Nitrogen containing compounds and adaptation of plants to salinity stress. Biol. Plant 43: 491-500.

NIEMAN R.H., CLARCK R.A. 1976. Interactive effects of salinity and phosphorus nutrition on the concentrations of phosphate and phosphate esters in mature photosynthesizing corn leaves. Plant Physiol. 57: 157-161.
QADAR A., ANSARI Z.M.A. 2006. Phosphorus requirements of rice grown in soils with different sodicity. J. Plant Nut. 29: 2105-2117.

ROGERS M.E., GRIEVE C.M., SHANNON M.C. 2003. Plant growth and ion relations in lucerne (Medicago sativa L.) in response to the combined effects of $\mathrm{NaCl}$ and P. Plant and Soil 253: $187-194$

SACAŁA E., DEMCZUK A., GRZYŚ E. SOBCZAK A. 2002. The effects of salt stress on growth and biochemical parameters in two maize varieties. Acta Soc. Bot. Pol. 71: 101-107.

SACAŁA E., BIEGUN A., DEMCZUK A., GRZYŚ E. 2005. Effects of $\mathrm{NaCl}$ and supplemental calcium on growth parameters and nitrate reductase activity in maize. Acta Soc. Bot. Pol. 74: $119-123$

SHUBHRA, DAYAL J., GOSWAMI C.L., MUNJAL R. 2004. Influence of phosphorus application on water relations, biochemical parameters and gum content in cluster bean under water deficit. Biol. Plant. 48: 445-448.

TALOUIZITE A., CHAMPIGNY M.L. 1988. Response of wheat seedlings to short-term drought stress with particular respect to nitrate utilization. Plant Cell Environ. 11: 149-155.

WARD M.R., ASLAM M., HUFFAKER R.C. 1986. Enhancement of nitrate uptake and growth of barley seedlings by calcium under saline conditions. Plant Physiol. 80: 520-524. 